\title{
A young male with massive haemoptysis and fever
}

\section{Patient history}

An 18-year-old male presented with recurrent episodes of massive haemoptysis. He expectorated three cups of bright red blood over a 24-hour period without haemodynamic failure. He also complained of shaking fever, left chest pain more prominent on breathing, fatigue and malaise. He had experienced a weight loss of $3 \mathrm{~kg}$ over a 2week period. He denied dyspnoea, sputum production, tobacco smoking and any contact with tuberculosis patients.

On physical examination, the patient was apparently in good health, with a body temperature of $38^{\circ} \mathrm{C}$, pulse rate 90 beats.minute- ${ }^{-1}$, blood pressure $130 / 80 \mathrm{mmHg}$, a respiratory rate of 22 breaths minute ${ }^{-1}$ and oxygen saturation $98 \%$ on room air. There was no clubbing or lymphadenopathy. Auscultation disclosed diminished breath sounds at the left lower hemithorax. The remainder of the physical examination was unremarkable.

In the past, the patient had been occasionally treated for lower respiratory infections because of cough and mild sputum production since the age of 15 years.

Laboratory investigation showed a

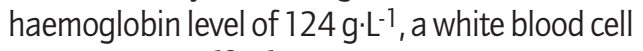
count of $6.0 \times 10^{12}$. L-1 (92\% neutrophils, 5\% lymphocytes), a haematocrit of 0.37 , a platelet count of $278 \times 10^{12} \cdot \mathrm{L}^{-1}$. Prothrombin time and international normalised ratio were within normal limits. Sedimentation was $60 \mathrm{~mm}$.hour ${ }^{-1}$. His routine biochemical investigations, which included renal and liver functions, and urine analysis, were all normal.

His chest radiography and computed tomography (CT) scans are shown in figures 1 and 2 .

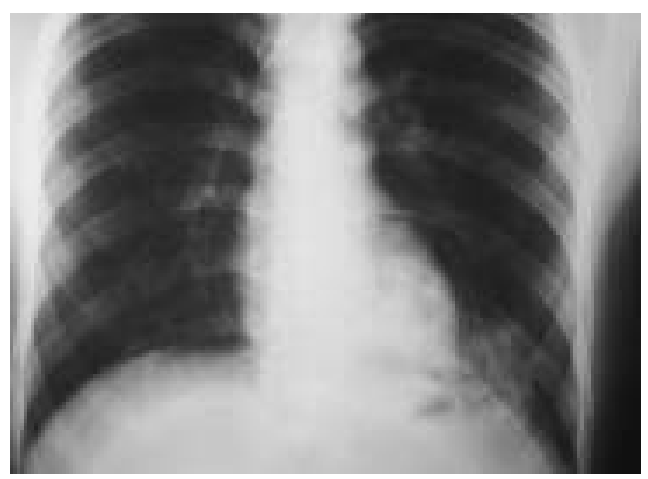

Figure 1

Chest radiograph at presentation.

\section{Task 1}

Interpret the chest radiograph.

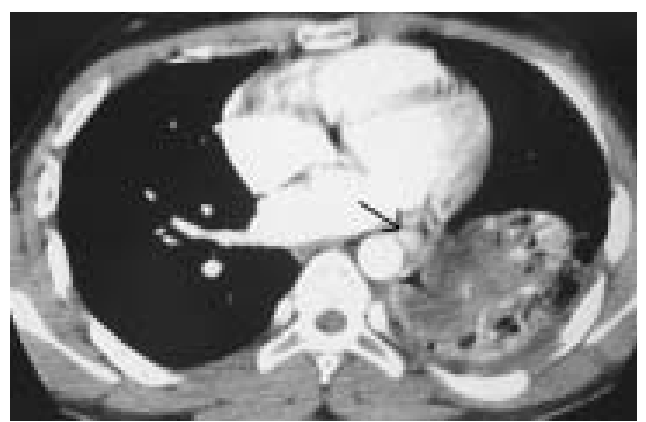

Figure 2

CT of the patient.

\section{Task 2}

Interpret the contract-enhanced CT scan.

Fibreoptic bronchoscopy revealed old blood clots bilaterally in the bronchial tree and the left lower lobe bronchus was completely obstructed with a blood clot. However, there was no active bleeding. A bronchoalveolar culture proved negative for fungal and acid-fast bacteria.

\section{Task 3}

What other diagnostic investigation would you suggest for suggest?
0. Uzun

A. Başoğlu

0. Aydın

0. Yeşildăg ${ }^{4}$

A. Dirican ${ }^{1}$

L. Erkan ${ }^{1}$

Depts of ${ }^{1}$ Pulmonary Medicine, ${ }^{2}$ Thoracic Surgery, ${ }^{3}$ Pathology and ${ }^{4}$ Cardiology, Faculty of Medicine, Ondokuz Mayss University, Samsun, Turkey.

\section{Correspondence:}

0. Uzun

19 Mayıs Universitesi, Tip Fak, Gögüs Hst. ABD 55139

Kurupelit-Samsun

Turkey

Fax: 903624576041

E-mail:oguzuzun@omu.edu.tr 


\section{Answer 1}

The chest radiograph at admission shows a well-defined non-homogenous opacity of 4-5 cm located adjacent to the left hemidiaphragm.

\section{Answer 2}

The CT scan of the chest shows a mass lesion of $10 \mathrm{~cm}$ in diameter, with lobulated borders at the left lower lobe adjacent to the descending aorta. Cystic areas were remarkable. An aberrant artery from the aorta was also seen (arrow). Areas of contrast enhancement can be seen within the mass.

\section{Answer 3}

An aortography was performed with a presumed diagnosis of bronchopulmonary sequestration (figure 3 ).

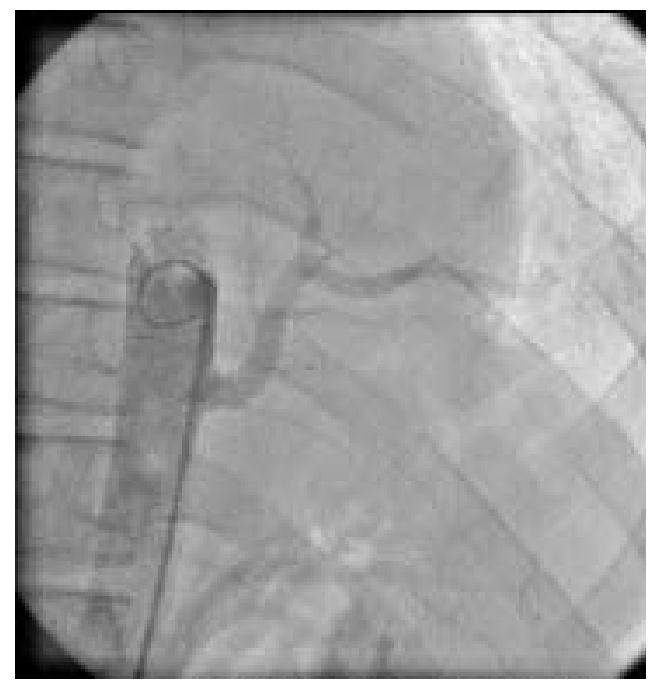

Figure 3

Aortogram of the patient.

Task 4

What does the aberrant artery seen on CT supply?

\section{Task 5}

What is your diagnosis?

\section{Answer 4}

The aortogram shows an aberrant vessel from the aorta that supplies the sequestrated segment of the left lower lobe.

\section{Answer 5}

\section{Bronchopulmonary sequestration.}

\section{Treatment and clinical course}

Intravenous cefuroxim sodium $750 \mathrm{mg}$ t.i.d. and clarithromycin $500 \mathrm{mg}$ b.i.d. was initiated on admission, which resulted in regression of fever, resolution of haemoptysis and improvement of the clinical situation.

The decision was made to excise the sequestrated segment after definite diagnosis for two main reasons:

1. to prevent recurrent massive haemorrhage into the bronchi, oesophagus or pleural cavity and a fatal outcome in the future; and

2. to prevent infective complications with the non-tuberculous bacteria, Mycobacterium tuberculosis, nocardial or fungal agents $[1,2]$.

Some 15 days after presentation, the patient underwent a left lower lobectomy. On exploration, there was marked enduration on posterior and lateral segments of the left lower lobe.

A 2-3-cm diameter extrapulmonary nodule on the posterior thoracic wall was excised (figure 4).

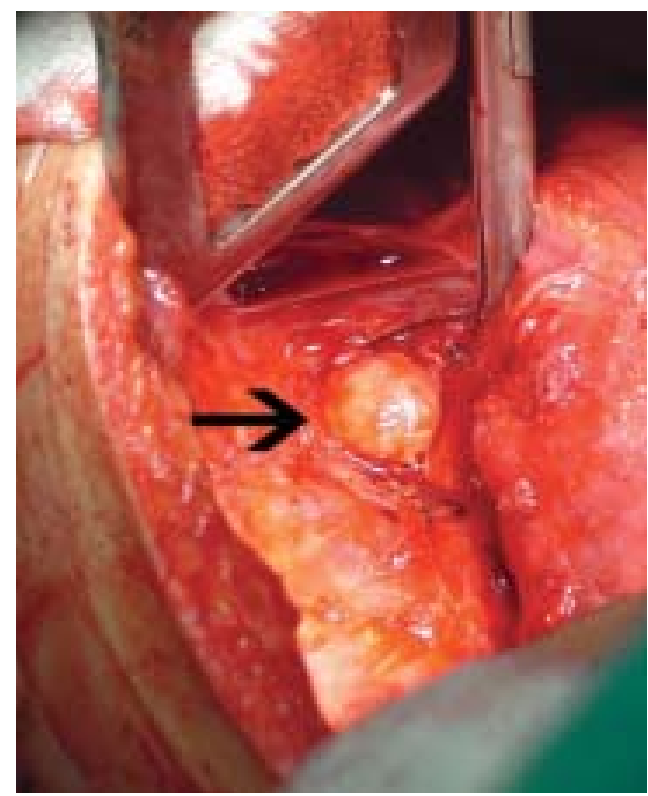

Figure 4

A 2-3-cm diameter nodule was observed on the posterior thoracic wall on exploration (arrow). 
A 1-cm diameter and 3-cm-long aberrant branch from the descending aorta was observed on operation (figure 5).

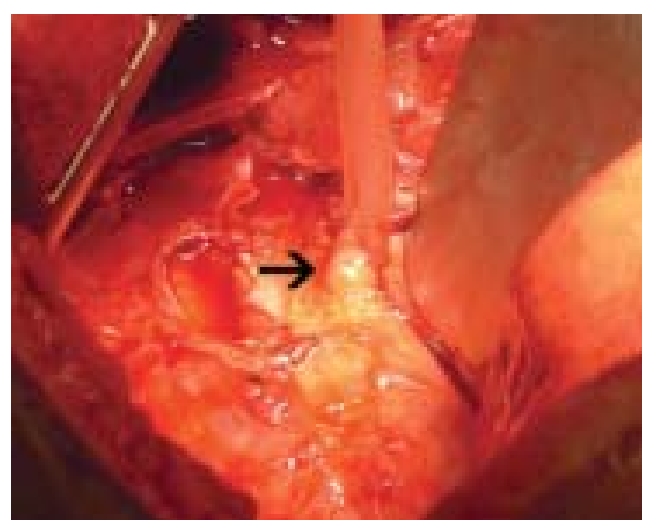

Figure 5

The aberrant branch from the descending aorta was observed on operation (arrow).

The post-operative period was uneventful and the patient left hospital on post-operative day 7 with no complications, and he remained healthy 7 months after the operation, without any complaints.

\section{Pathology}

Macroscopically, there were two haemorrhagic lesions, which were $18 \times 20 \times 18 \mathrm{~cm}$ and $3 \times 2 \mathrm{~cm}$ in diameter. Microscopically, multiple cystic spaces were observed, which contained foamy macrophages and amorphous eosinophilic material in the first lesion (figure 6). Cyst walls were lined with pseudostratified ciliated respiratory epithelium and alveoli were surrounded by marked inflammation. Thick-walled systemic vessels were also remarkable in the interstitium.

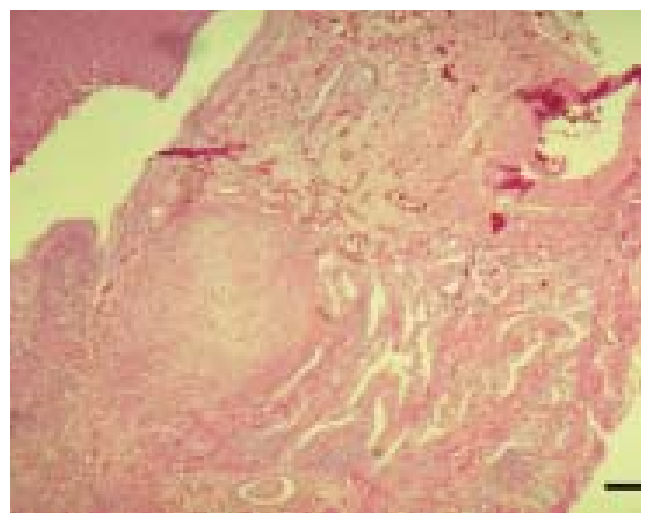

Figure 6

Histological appearance of the resected specimen, showing peripherally located compressed alveoli, a cystic space lined by pseudostratified ciliated respiratory epithelium and thick-walled systemic vessels. Haematoxylin and eosin stained. Internal scale bar $=300 \mu \mathrm{m}$.
The second lesion, which was extralobary, contained dilated and cartilage-bound bronchi histologically and was surrounded by fibro-adipose tissue.

\section{Discussion}

Bronchopulmonary sequestration is a rare congenital malformation in which a portion of pulmonary tissue is detached from the remainder of the normal lung and receives its blood supply from a systemic artery. Two forms of the anomaly are commonly described: intralobar sequestration (ILS) lies contiguous with normal lung parenchyma and within the same visceral pleura; and extralobar sequestration (ELS) is enclosed within its own pleural membrane, usually in close proximity to the normal lung, but sometimes within or below the diaphragm. ILS is the most common form of classic pulmonary sequestration and accounts for $75 \%$ of all sequestrations [3]. ELS is less common than ILS, accounting for $\sim 25 \%$ of cases [4]. The patient presented here had both ILS and ELS, which is very rare in the literature [4].

The term sequestration was first introduced by Pyrce in 1946 to describe a disconnected bronchopulmonary mass with anomalous arterial supplies involving the lung [5]. There are many variants of sequestration that do not strictly meet these criteria. This spectrum ranges from normal vessels supplying abnormal lung to abnormal vessels supplying normal lung [6]. The sequestration in the patient presented here can be classified as type 3 according to Pryce's original classification, in which type an abnormal artery supplies only the sequestered segment. Pryce has also described two other types of sequestration: in type 1 , there is an abnormal artery without sequestration; and, in type 2, abnormal artery supplies the sequestered as well as the adjacent normal lung.

Most patients with bronchopulmonary sequestration present with recurrent acute pulmonary infections, but usually not before adulthood [7]. The presentation may be mistaken for bronchiectasis or a lung abscess. It should be noted that the patient can be asymptomatic, and that sequestration can be discovered incidentally on chest radiography [8]. The current patient had experienced recurrent pulmonary infections since the age of 15 years. Haemorrhage can occur in the bronchial tree [9], oesophagus [10] or pleural cavity $[11,12]$. Minor haemoptysis, usually occurring in association with infections, is a frequent presentation of the disease; however, massive haemoptysis [13-16], as in this patient, is an extremely rare complication of 
bronchopulmonary sequestration, and it can even be fatal [9]. It results from rupture of the abnormal pulmonary vessels in the affected lung, caused by chronic recurrent infections and pulmonary hypertension, resulting from transmission of systemic pressure to the affected lung.

The most common radiographic presentation of ILS is as a homogeneous opacity in the posterior basal segment of a lower lobe, usually the left and, almost invariably, contiguous with the hemidiaphragm, as in the current patient [6]. Less often, a cystic mass may be prominent in the base of one lung. The CT findings consist most commonly of a well-circumscribed mass and, in some cases, when the disease is complicated, cystic areas, as seen in the present patient's CT scan [6]. CT scans can also show aberrant vessels supplying the sequestration [17].

The pathogenesis of bronchopulmonary sequestration is controversial. Some believe that both ILS and ELS are embryonic in origin. That is, separation of abnormally caudal foregut budding from the tracheobronchial tree with retention of embryonic systemic arterial connection [18, 19]. However, citing the infrequency of this finding in neonates and stillborn infants $[20,21]$, some investigators contend that very few $(<5 \%)$ are embroynic in origin and that an acquired cause more appropriately explains the changes observed [4, 21-23]. Chronic inflammatory processes, such as pneumonia and tuberculosis [22 or foreign body aspiration [21], have been hypothesised as causes of acquired ILS. According to this view, the initial event in the formation of intralobar sequestration is focal bronchial obstruction. Persistence of the obstruction and inflammation leads to the characteristic cystic and fibrotic changes in lung parenchyma. The initial inflammatory process also interrupts pulmonary blood flow into the affected lung segment; hypertrophy of systemic arteries then results in "anomalous" vascular supply.

The definitive diagnosis of sequestration is classically based on the demonstration of an aberrant systemic arterial supply by angiography. Magnetic resonance imaging $[18,19]$ and spiral CT angiography [17] have also been used for noninvasive diagnosis of the disease in recent years. The treatment of choice should be surgical resection of the sequestrated segment in order to prevent massive haemorrhagic and recurrent suppurative complications.

\section{References}

1. Schachter EN, Karpick RJ. Bronchopulmonary sequestration and pulmonary tuberculosis. Chest 1972; 62: 331-333.

2. Mattila SP, Ketonen PES, Kyllönen KEJ, et al. Pulmonary sequestration associated with tuberculosis, aspergillosis and pseudomycosis. Ann Chir Gynaecol Fenn 1975; 64: 30-35.

3. Savic B, Birtel FJ, Knoche R, Tholen W, Schild H. Pulmonary sequestration. In: Frick HP, Harnack GA, Martini GA, et al., eds. Advances in Internal Medicine and Pediatrics. Berlin, Springer-Verlag, 1979; pp. 58-92.

4. Savic B, Birtel FJ, Tholen W, et al. Lung sequestration: report of seven cases and review of 540 published cases. Thorax 1979; $34: 96-101$.

5. Pyrce DM. Lower accessory pulmonary artery with intralobar sequestration of lung: report of seven cases. J Pathol 1946; 58: $457-467$.

6. Felker RE, Tonkin ILD. Imaging of pulmonary sequestration. AJR Am J Roentgenol 1990; 154: $241-249$.

7. Durnin RE, Lababidi Z, Butler C, et al. Bronchopulmonary sequestration. Chest 1970; 57: 454-459.

8. John PR, Beasley SW, Mayne V. Pulmonary sequestration and related congenital disorders. A clinico-radiological review of 41 patients. Pediatr Radiol 1989; $20: 4-9$.

9. Rubin EM, Garcia H, Horowitz MD, et al. Fatal massive hemoptysis secondary to intralobar sequestration. Chest 1994; 106: 954-955.

10. Arroya JG, James G. Bronchopulmonary sequestration as a rare cause of acute, massive intraesophageal bleeding. South Med J $1983 ; 76: 241-242$.

11. Zapatero J, Baamonde C, Bellan JM, et al. Hemothorax as a rare presentation of intra pulmonary sequestration. Scan J Thorac Cardiovasc Surg 1983; 17: 177-179.

12. Pratter MR, Kaemmerlan JT, Erickson AD. Bloody pleural effusion associated with an intralobar pulmonary sequestration. Chest $1979 ; 75: 393-395$.

13. Bruhlmann W, Weishaupt D, Goebel B, et al. Therapeutic embolization of a systemic arterialization lung without sequestration. Eur Radiol 1998; 8: 355-358.

14. Painter RL, Billing DM, Epstein I. Anamalous systemic arterialization of the lung without sequestration. N Engl J Med 1968; $279: 866-867$.

15. Gamondes JP, Devolfe C, Morin A, et al. Sequestration pulmonaire intra-lobaire du Type 1 de Pryce. Rev Pneumol Clin 1984; 40: $209-213$.

16. Flisak ME, Chandrasekar AJ, Marsan RE, et al. Systemic arterialization of lung without sequestration. AJR Am J Roentgenol 1982; $138:$ 751-753.

17. Franco J, Aliaga R, Domingo ML, Plaza P. Diagnosis of pulmonary sequestration by spiral CT angiography. Thorax 1998; 53: 1089-1092.

18. Matzinger FR, Bhargava R, Peterson RA, et al. Systemic arterial supply to the lung without sequestration: an unusual cause of hemoptysis. Can Assoc Radiol J 1994; 45: 44-47.

19. Garcia-Pena P, Lucaya J, Hendry GM, et al. Spontaneous involution of pulmonary sequestration in children: a report of two cases and review of the literature. Pediatr Radiol 1998; 28: 266-270.

20. Holder PD, Langston C. Intralober pulmonary sequestration (a nonentity?). Pediatr Pulmonol 1986; 2: $147-153$.

21. Stocker JT, Malczak HT. A study of pulmonary ligament arteries. Relationship to intralobar pulmonary sequestration. Chest 1984; 86: 611-615.

22. Freeman RK, Maxwell JM. Intralober bronchopulmonary sequestration presenting as hemoptysis: evidence for an acquired cause. Mil Med 1998; 163: 502-503.

23. Gebebauer PW, Mason CR. Intralober sequestration associated with anomalous pulmonary vessels. Dis Chest 1959; 35: $282-288$.

24. Doyle AJ. Demonstration of blood supply to pulmonary sequestration by MR angiography. AJR Am J Roentgenol 1992; 158: 989-990.

25. Au VW, Chan JK, Chan FL. Pulmonary sequestration diagnosed by contrast enhanced three-dimensional MR angiography. Br J Radiol $1999 ; 72: 709-711$. 